Int. J. Electrochem. Sci., 11 (2016) $6356-6369$

\title{
Enhancement of Electrochemical Glucose Sensing by Using Multiwall Carbon Nanotubes decorated with Iron Oxide Nanoparticles
}

\author{
E.G. Uc-Cayetano ${ }^{1}$, L.C. Ordóñez ${ }^{2, *}$, J.V. Cauich-Rodríguez ${ }^{1}$, F. Avilés ${ }^{1}$ \\ ${ }^{1}$ Centro de Investigación Científica de Yucatán, Unidad de Materiales, Calle 43 \# 130, Col. Chuburná \\ de Hidalgo, 97200 Mérida, Yucatán, México. \\ ${ }^{2}$ Centro de Investigación Científica de Yucatán, Unidad de Energía Renovable, Carretera Sierra \\ Papacal-Chuburná Puerto km. 5, 97302 Sierra Papacal, Yucatán, México. \\ *E-mail: $\underline{\text { lcol@ cicy.mx }}$
}

doi: $10.20964 / 2016.07 .85$

Received: 15 April 2016 / Accepted: 23 May 2016 / Published: 4 June 2016

\begin{abstract}
The influence of iron oxide nanoparticles decorating the external surface of multiwall carbon nanotubes (MWCNTs) on the amperometric sensing of glucose in solution is investigated. Oxidized nanotubes are decorated with iron oxide nanoparticles and then glucose oxidase is chemically bound to the MWCNTs for glucose sensing within physiological levels. MWCNTs which are only oxidized (without decorating nanoparticles) are used as reference. The results of the electrochemical characterizations consistently show that the presence of iron oxide nanoparticles decorating the surface of MWCNTs enhance the amperometric response and the sensitivity to increments in glucose concentration, when compared to non-decorated MWCNTs. The biosensor containing iron oxide decorated nanoparticles showed an amperometric sensitivity of $4.75 \mu \mathrm{A} / \mathrm{mMcm}^{2}$ and an average response time of $6.6 \mathrm{~s}$.
\end{abstract}

Keywords: Carbon nanotubes, iron oxide, glucose sensing.

\section{FULL TEXT}

(C) 2016 The Authors. Published by ESG (www.electrochemsci.org). This article is an open access article distributed under the terms and conditions of the Creative Commons Attribution license (http://creativecommons.org/licenses/by/4.0/). 